\title{
GEOTECNOLOGIAS APLICADAS À ANÁLISE ESPAÇOTEMPORAL DO USO E DA OCUPAÇÃO DA TERRA NA PLANÍCIE COSTEIRA DE CARAVELAS $(B A)^{1}$
}

\author{
GEOTECHNOLOGIES APPLIED TO TIME-SPACE ANALYSIS OF LAND USE \\ AND OCCUPATION IN COASTAL PLAIN OF CARAVELAS (BA) \\ LAS GEOTECNOLOGÍAS APLICADAS AL ANALISIS ESPACIO-TIEMPO DEL \\ USO Y OCUPACIÓN DE TERRENOS EN LLANO COSTERO CARAVELAS (BA)
}

\author{
Sirius Oliveira Souza - Universidade Estadual de Campinas - Campinas - São Paulo - Brasil \\ siriussouza@ige.unicamp.br
}

\begin{abstract}
Resumo
0 objetivo deste artigo é diagnosticar as principais formas de uso e ocupação da terra na Planície Costeira de Caravelas, no extremo sul da Bahia, ao longo dos anos de 1984, 1991, 2006 e 2011. Sua área é de aproximadamente $580 \mathrm{~km}^{2}$, localizada entre os paralelos $17^{\circ} 37^{\prime} 52^{\prime \prime} \mathrm{S}$ e $17^{\circ} 51^{\prime} 44^{\prime \prime} \mathrm{S}$ e os meridianos $39^{\circ} 22^{\prime} 7^{\prime \prime}$ e $39^{\circ} 12^{\prime} 7.11^{\prime \prime} \mathrm{W}$ de Greenwich. Para este diagnóstico, foram utilizadas como base as imagens orbitais do Satélite Landsat-TM, posteriormente integradas e processadas no Sistema de Informação Geográfica, pelo software ArcGis, por meio da classificação híbrida. Os resultados comprovam a gradativa expansão da área agrícola, da área urbana e da pastagem. Paralelamente há a redução das áreas ocupadas pelos corpos d'água e pelos Manguezais e brejos. 0 mapeamento realizado pretende contribuir com os estudos de evolução da paisagem e subsidiar melhores propostas de planejamento para o uso e a ocupação da terra nessa planície.
\end{abstract}

Palavras-chave: uso e ocupação da terra, classificação híbrida, Caravelas, geotecnologias.

\section{Abstract}

The objective of this study is Diagnose the main forms of land use and occupation of the Caravelas Coastal Plain over the years 1984, 1991, 2006 and 2011. The study area is the Caravelas Coastal Plain, inserted in the extreme south of Bahia state, occupying an area of $580 \mathrm{~km}^{2}$, located between the parallels $17^{\circ} 37^{\prime} 52$ "S and $17^{\circ} 51^{\prime} 44^{\prime \prime} \mathrm{S}$ and the meridians $39^{\circ} 22^{\prime} 7$ "and $12^{\prime} 7.11^{\circ} 39^{\prime} \mathrm{W}$ of Greenwich. For this diagnosis was used as basis the satellite images obtained by using LandsatTM subsequently integrated and processed in GIS at ArcGIS software using the hybrid classification. The results obtained confirm the gradual expansion of the agricultural area, urban area and pasture. In parallel the reduction of areas occupied by water bodies, wetlands and mangroves. The mapping carried out intend to contribute to studies of landscape evolution and support better planning proposals for the use and occupation of land along the Caravelas Coastal Plain .

Key words: use and occupation of the land, hybrid classification, Caravelas, geotechnologies.

\section{Resumen}

El objetivo del presente trabajo es diagnosticar las principales formas de uso y la ocupación de la tierra de los Ilano costero Caravelas durante los años 1984, 1991, 2006 y 2011. El área de estudio es Ilano costero Caravelas, insertadas en el extremo sur del estado de Bahía, que ocupan una superficie de 580 kilometros ${ }^{2}$, situado entre los paralelos $17^{\circ} 37^{\prime} 52^{\prime \prime S}$ y $17^{\circ} 51^{\prime} 44^{\prime \prime}$ S y los meridianos $39^{\circ} 22^{\prime} 7$ "y $12^{\prime} 7.11^{\circ} 39^{\prime} \mathrm{W}$ de Greenwich. Para este diagnóstico se utilizó como base las imágenes de satélite obtenidas mediante el uso de LandsatTM posteriormente integrada y procesada en el SIG en software ArcGIS utilizando la clasificación híbrida. Los resultados obtenidos confirman la progresiva expansión de la superficie agrícola, área urbana y pastos. Junto a la reducción de las áreas ocupadas por las masas de agua, los pantanos y los manglares. El estudio busca 
contribuir a los estudios de la evolución del paisaje y apoyar mejores propuestas de planificación para el uso y ocupación del suelo a lo largo de los llano costero Caravelas.

Palabras clave: uso y ocupación de la tierra, clasificación híbrida, Caravelas, geotecnologías.

\section{Introdução}

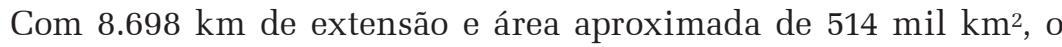
litoral brasileiro constitui-se em um contínuo desafio à gestão em face da diversidade de problemáticas ali existentes. "São aproximadamente 300 municípios defrontantes com o mar, os quais têm, na faixa de praia, um espaço privilegiado para o desenvolvimento de atividades turísticas, de lazer, de pesca, dentre outras" (Nicolodi e Peterman, 2010).

É nesse cenário enérgico e de alta variabilidade, tanto socioeconômica quanto física, que residem aproximadamente $18 \%$ da população do país, sendo que 16 das 28 regiões metropolitanas encontram-se no litoral (Nicolodi e Peterman, 2010, p. 158). Segundo os autores, essas áreas de elevada saturação populacional convivem com amplas extensões de povoamento esparso e rarefeito - o habitat das comunidades de pescadores artesanais, dos remanescentes de comunidades quilombolas, de tribos indígenas e de outros agrupamentos tradicionais.

O litoral, como recorte regional para estudo e como base para o tratamento de políticas públicas é uma realidade, tendo em vista a densa ocupação desta área, gerada, dentre outros fatores, por distintos méritos, tais como disponibilidade de recursos naturais, facilidade de acesso, proximidade com a costa propriamente dita e beleza cênica. Esses interesses se relacionam de forma intensa à produção do espaço, ora se integrando, ora competindo e oportunizando o surgimento de conflitos. Assim, o Brasil insere-se, historicamente, no processo de concentração produtiva e, consequentemente, populacional do litoral (Moraes, 2007).

Ainda segundo Moraes (2007), na zona costeira do estado da Bahia, a densidade demográfica média é de $96 \mathrm{hab} / \mathrm{km}^{2}$. Tal dado se encontra acima da densidade nacional que é de $22 \mathrm{hab} / \mathrm{km}^{2}$, segundo o mesmo autor. No entanto, esse valor é baixo em relação aos estados de Pernambuco e do Rio de Janeiro com 913 hab/km² e 806 hab/km², respectivamente. Dessa forma, em razão da moderada densidade populacional da costa da Bahia, ela pode ainda ser planejada/pensada de forma a minimizar a vulnerabilidade encontrada em outros trechos da costa brasileira. 
Ao longo do litoral baiano, optou-se por estudar a Planície Costeira de Caravelas, localizada no extremo sul do estado, com cerca de $580 \mathrm{~km}^{2}$ de área, compreendendo parte dos municípios de Alcobaça, Nova Viçosa e Caravelas. A escolha justifica-se pela sua extensão quando comparada com as demais planícies costeiras do Brasil, bem como pela sua representatividade ecológica, considerada um santuário ecológico, atestado pela existência da Reserva Extrativista de Cassurubá2 (Figura 1).

A utilização das geotecnologias serviu de subsídio ao foco principal deste trabalho, que tem como objetivo diagnosticar as principais formas de uso e ocupação da terra na nessa planície ao longo dos anos de 1984, 1991, 2006 e 2011.

No que se refere às geotecnologias, o avanço dos instrumentos computacionais e dos métodos automatizados de análise das informações espaciais tem contribuído consideravelmente com uma ampliação das categorias de estudo do espaço geográfico, gerando novos conhecimentos do ambiente e das variáveis atuantes na dinâmica de transformação do espaço produzido pelo homem.

O próprio termo geotecnologias apresenta várias definições dentro da comunidade científica, até mesmo por se tratar de uma temática recente e por trazer em sua base aspectos integrante de várias áreas do conhecimento, como a associação de aparatos computacionais às variáveis espaciais. Neste texto, entende-se geotecnologias como

o conjunto de tecnologias para coleta, processamento, análise e oferta de informações como referência geográfica. As geotecnologias são compostas por soluções em hardware, software e peopleware que juntos constituem poderosas ferramentas para tomada de decisões. (Rosa, 2005, p. 5)

Frequentemente o termo é utilizado para designar um conjunto de aparatos tecnológicos relacionados à computação (hardware, software, peopleware, arquitetura de banco de dados, metodologias de análise), aliados aos conhecimentos científicos que lhes são necessários para realizar a aquisição, o tratamento e a produção de informações de forma georreferenciada, agregando, portanto, o Sensoriamento Remoto, a Cartografia Digital, o Sistema de Posicionamento Global (GPS) e os Sistemas de Informações Geográficas (GIS) (Matias, 2001).

O seu uso dentro da ciência geográfica permite um avanço metodológico na análise de uso e ocupação da terra, visto que, ao agregar estas 
novas técnicas à pesquisa científica, amplia as possibilidades de inferência sobre o ambiente, o que acentua a importância da reflexão sobre os resultados, e demonstra a fundamental relevância para se unir o que as novas tecnologias da informação têm a acrescentar à construção do conhecimento científico.

Nesta construção de conhecimento e obtenção de informações sobre a superfície terrestre, as técnicas de geoprocessamento e sensoriamento remoto tornam-se imprescindíveis, constituindo hoje um conjunto de ferramentas indispensáveis em planejamentos e zoneamentos. A confiabilidade e a rapidez no processo de sensoriamento permitem uma maior facilidade na aquisição dos dados que é de grande importância para o mapeamento de uso e ocupação do solo numa determinada região.

O conhecimento das formas de ocupação do espaço é de grande importância aos planejadores e legisladores para que sejam tomadas as melhores medidas, caso necessário, em relação ao uso da terra, e também para que essas medidas possam ser revisadas, buscando promover a adequação dos usos às suas diversas características. Reconhecer os ambientes garante ao homem a sua sobrevivência, seja como protagonista, ao extrair recursos do meio, seja como figurante, ao possibilitar a conservação do princípio socioeconômico vigente (Bernardes e Ferreira, 2003).

Material e métodos

\section{Caracterização da área em estudo}

A Região Planície Costeira de Caravelas (Figura 1) se localiza no extremo sul da Bahia, precisamente na faixa costeira Costa das Baleias, abrangendo parte dos municípios de Alcobaça, Caravelas e Nova Viçosa. Situando-se entre os paralelos $17^{\circ} 37^{\prime} 52^{\prime \prime}$ e e $17^{\circ} 51^{\prime} 44^{\prime \prime S}$ e os meridianos $39^{\circ} 22^{\prime} 7^{\prime \prime}$ e $39^{\circ} 12^{\prime} 7.11^{\prime \prime} \mathrm{W}$ de Greenwich, esta planície se limita ao norte pela bacia do rio Itanhém, ao sul e a oeste pela bacia do rio Peruípe e a leste ao Oceano Atlântico.

O clima da região é classificado como do tipo tropical, superúmido a úmido, sem estação seca (IBGE, 2007), com valores de precipitação em torno de $1.350 \mathrm{~mm}$, sendo que esses valores diminuem em direção ao interior do continente. A Floresta Ombrófila Densa e as Formações Pioneiras contribuem com o desenvolvimento dos tipos de cobertura vegetal (Dominguez, 2008). 


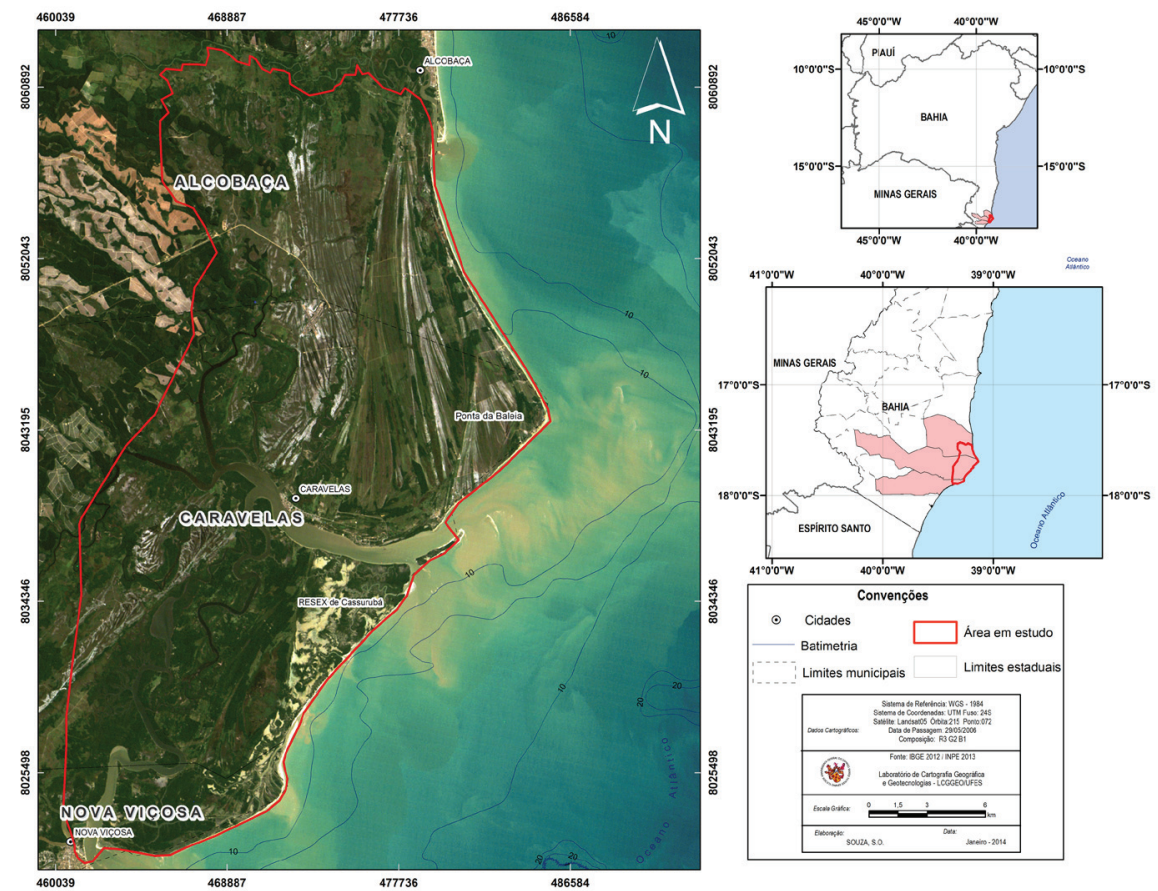

Figura 1- Mapa de localização da Planície Costeira de Caravelas (BA).

Tomando como base os remanescentes e gradientes ecológicos, o autor esclarece que, na região estudada, a Floresta Ombrófila Densa (Mata Atlântica) ocupa os tabuleiros costeiros e as porções mais úmidas das serras próximas ao litoral. Essa formação conglomera um diversificado mosaico de ecossistemas florestais com estruturas e composições florísticas bastante individualizadas, tendo como elemento comum a exposição aos ventos úmidos oceânicos. Ainda segundo o autor, essa cobertura vegetal está praticamente ausente, restando apenas alguns remanescentes nas vertentes dos vales encaixados da Formação Barreiras. Tal conjuntura se faz especialmente em virtude da introdução de áreas de pastagens, silvicultura, sobretudo eucalipto, e lavouras de ciclos curtos.

No que se refere às Formações Pioneiras, Dominguez (2008) afirma que elas ocupam áreas na planície costeira de idade quaternária, compreendendo áreas de influência marinha, fluvial e fluviomarinha. As áreas 
de influência marinha compreendem os espaços cujo substrato arenoso é coberto por vegetação do tipo mata seca de restinga, enquanto as áreas de influência fluvial, sujeitas às inundações cíclicas ao longo dos rios, são recobertas por formações herbáceo-graminoides. Já as áreas de influência fluviomarinha são caracterizadas pelas oscilações das marés e pelo substrato argiloso, no qual se desenvolve a vegetação que compõe os manguezais. Embora tenham sido pontualmente alteradas, segundo o autor, tais formações encontram-se ainda bem conservadas.

Em âmbito geológico-geomorfológico, a Região Planície Costeira de Caravelas está assentada secundariamente sobre os sedimentos arenoargilosos de idade terciária da Formação Barreiras, que se distinguem pela existência de vales profundos e bordas escarpadas, e uma superfície geral inclinada em direção ao litoral, constituindo os tabuleiros costeiros, e principalmente sobre a planície quaternária, constituída por depósitos de areias litorâneas regressivas pleistocênicas e holocênicas. Tais depósitos encerraram sua acumulação controlada pelas variações do nível relativo do mar que afetaram a costa brasileira durante o Quaternário (Andrade e Dominguez, 2002).

\section{Procedimentos metodológicos}

Para alcançar os objetivos propostos neste estudo, ele foi dividido em três principais etapas: a primeira é composta de revisão bibliográfica acerca do uso e da ocupação da terra em planícies costeiras; a segunda, composta pela aquisição das imagens Landsat-TM e a realização de trabalhos de campo, pautados na observação e nos registros das classes de uso e ocupação presentes; e a terceira etapa é caracterizada pela integração dos dados levantados em campo com os dados do sensor Landsat-TM em ambiente SIG, com uso do software ArcGIS ${ }^{\mathrm{TM}} 10.1$ e pela redação final da pesquisa. Apresenta-se a seguir, o detalhamento dos principais procedimentos relativos à segunda e à terceira etapa.

Os mapas de uso e ocupação da terra na Região Planície Costeira de Caravelas foram confeccionados a partir da classificação híbrida ${ }^{3}$ de imagens orbitais, em que cada pixel na imagem é rotulado de acordo com um tipo de uso e ocupação. A classificação de imagens orbitais pode ser efetuada de forma supervisionada, não supervisionada e híbrida. Neste estudo, optou-se pela classificação supervisionada híbrida. 
Neste estudo foram utilizadas as imagens referentes à órbita de número 215 e ponto 072, em virtude da busca por imagens com menor quantidade possível de nuvens, menor excesso de brilho e maior normalidade espectral. Após a escolha das imagens, estas foram georreferenciadas, usando como base a folha topográfica do IBGE, que cobre a área em estudo, na escala 1:150.000 em formato digital. Posteriormente, os dados foram processados no software Arc Gis ${ }^{\circledR} 10.1$.

A seguir, foram escolhidas as chaves de interpretação representativas de cada uma das classes de interesse para o algoritmo de classificação supervisionada. Dentre os tipos de algoritmos supervisionados, os mais utilizados são a máxima verossimilhança (Maxver), paralelepípedo e a distância euclidiana (Moreira, 2005). Neste caso, foi utilizada a máxima verossimilhança por ser o tipo que fornece classificações com as melhores precisões.

As classes de uso e ocupação da terra presentes na área foram observadas e registradas durante os trabalhos de campo realizados em março de 2013. Posteriormente, em ambiente SIG, elas foram conceituadas com base em Nascimento e Dominguez (2009), adaptadas conforme o Manual técnico de uso da terra, do IBGE (2013), e podem ser observadas na tabela a seguir:

Tabela 1- Classes estabelecidas para o uso e ocupação da Planície Costeira de Caravelas.

\begin{tabular}{|c|c|}
\hline $\begin{array}{c}\text { Letra símbolo } \\
\text { das classes }\end{array}$ & Categorias \\
\hline TU/C & Área Urbana \\
\hline TA & Área Agrícola \\
\hline $\mathrm{P}$ & Pastagem \\
\hline TF & Área Florestal \\
\hline TU & Manguezais/brejos \\
\hline TA & Solo Exposto \\
\hline TCA & Corpos d'água \\
\hline
\end{tabular}

Fonte: Nascimento e Dominguez (2009).

Por fim, para gerar estes mapas, dentro do software escolhido, foi utilizado o comando Create Signatures para criar as chaves de identificação espectral, seguido pelo comando Maximum Likelihood Classification para realizar a classificação. Converteram-se os rasters para a modalidade vetorial com o comando Raster to Polygon, foram feitas algumas correções 
necessárias editando a tabela de atributos e calculados os respectivos valores em área pelo comando Geometry Calculator.

A definição e o entendimento de cada classe de uso e ocupação da terra são apresentados na Tabela 2:

Tabela 2- Unidades de uso e ocupação da terra e valores de vulnerabilidade ambiental.

\begin{tabular}{|c|c|}
\hline Símbolo & Categoria de uso da terra e associações de uso da terra \\
\hline \multicolumn{2}{|r|}{ Área urbana } \\
\hline TUCc & Núcleo urbano consolidado: cidade \\
\hline TUCv & Vila \\
\hline TUCh & $\begin{array}{l}\text { Área com empreendimento hoteleiro, bar e restaurante, associada à } \\
\text { cultura de coco }\end{array}$ \\
\hline TUCrl & $\begin{array}{l}\text { Área com equipamento residencial (sítio) ou loteada para veraneio, } \\
\text { associada à cultura de coco }\end{array}$ \\
\hline TUCic & Área da indústria de celulose \\
\hline TUCo & $\begin{array}{l}\text { Área com uso de argila e/ou caulim para a fabricação de tijolo, telha e/ou } \\
\text { cerâmica: olaria }\end{array}$ \\
\hline ETE & Estação de Tratamento de Esgoto \\
\hline \multicolumn{2}{|r|}{ Área agrícola } \\
\hline TAco & Cultura de coco-da-baía em área de restinga \\
\hline TAcn & Cana-de-açúcar em aluvião \\
\hline TAs & Silvicultura: maciço florestal homogêneo de eucalipto \\
\hline TAcd & $\begin{array}{l}\text { Cultura diversificada; frutífera (mamão, coco-da-baía, banana, abacaxi, } \\
\text { maracujá, principalmente) e pequena gleba com mandioca, milho, feijão } \\
\text { ou pastagem }\end{array}$ \\
\hline \multicolumn{2}{|r|}{ Pastagem } \\
\hline $\mathrm{Pl}$ & Pastagem semi-intensiva destinada principalmente à pecuária leiteira \\
\hline Pc & $\begin{array}{l}\text { Pastagem semi-intensiva destinada principalmente à pecuária de corte, } \\
\text { associada a pequenas parcelas de cultivo de mandioca }\end{array}$ \\
\hline Psvg & Terra sem cobertura vegetal ou desmatada com finalidade agropastoril \\
\hline \multicolumn{2}{|r|}{ Área florestal } \\
\hline TFo & Floresta Ombrófila Densa em estágio inicial e médio de antropismo \\
\hline TFoC & $\begin{array}{l}\text { Floresta Ombrófila Densa em estágio avançado de antropismo ou } \\
\text { vegetação secundária - capoeira }\end{array}$ \\
\hline TFmr & Mata de Restinga \\
\hline TFra & Restinga arbustiva \\
\hline TFrh & $\begin{array}{l}\text { Restinga herbácea com trecho associado à pastagem nativa e/ou cultivo de } \\
\text { coco-da-baía e a pequenas glebas de cultivo de subsistência }\end{array}$ \\
\hline
\end{tabular}




\begin{tabular}{|c|c|}
\hline Símbolo & Categoria de uso da terra e associações de uso da terra \\
\hline \multicolumn{2}{|r|}{ Manguezais e brejos } \\
\hline TUmg & $\begin{array}{l}\text { Manguezais, uso comercial e pesca artesanal de crustáceo e molusco } \\
\text { associada à planície de maré. }\end{array}$ \\
\hline TUvaa & Terra com vegetação arbustiva e/ou arbórea, de pântano ou brejo \\
\hline TUvh & $\begin{array}{l}\text { Terra com vegetação herbácea de brejo, pastada por rebanho bovino em } \\
\text { determinado período do ano }\end{array}$ \\
\hline \multicolumn{2}{|r|}{ Solo exposto } \\
\hline TAsp & Sedimento de praia atual \\
\hline \multicolumn{2}{|r|}{ Corpos d'água } \\
\hline TCAcr & Reservatório destinado principalmente à carcinicultura: camarão \\
\hline TCAcr & Rio permanente \\
\hline \multirow[t]{2}{*}{ La } & Lagoa permanente \\
\hline & Outros \\
\hline $\mathrm{Ni}$ & Uso não identificado \\
\hline
\end{tabular}

Fonte: Nascimento e Dominguez (2009).

Resultados e discussões

Uso e ocupação da terra na Planície Costeira de Caravelas no período de 1984 e 2011

Mediante a análise do comportamento espectral dos alvos e dos trabalhos de campo realizados na Planície Costeira de Caravelas, tornou-se possível observar o uso e a ocupação da terra em 1984, 1991, 2006 e 2011. Assim, apresentam-se a seguir os resultados espacializados nas Figuras 2, 3, 4 e 5, com base nas categorias descritas anteriormente.

Verifica-se a presença das pastagens enquanto matriz da Planície Costeira de Caravelas, representada pela existência de campos herbáceo-graminoides introduzidos ou pelas terras apenas desmatadas com finalidade agropastoril. Autores como Souza, Germani e Souza (2011), Limonad (2008), Fontes e Mello e Silva (2005), dentre outros, confirmam o predomínio de pastagens semi-intensivas destinadas, sobretudo, à pecuária de corte e à pecuária leiteira.

No período estudado, percebe-se um contínuo aumento das áreas ocupadas por pastagens, totalizando um aumento absoluto de $58 \mathrm{~km}^{2}$, ou seja, de aproximadamente 9,91\%, fator que se explica pela realidade econômica local, que era sustentada principalmente por atividades relacionadas à agropecuária, o que denota sua ocupação em 2011 de aproximadamente $227,52 \mathrm{~km}^{2}$, ou seja, 39,16\% da área em estudo. 


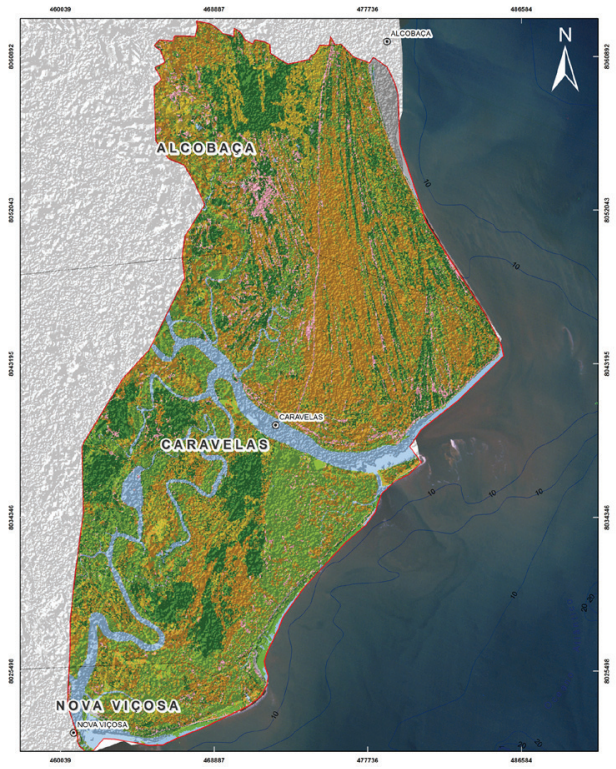

Uso e Ocupação das Terras na Região Planície Costeira de Caravelas em 1984

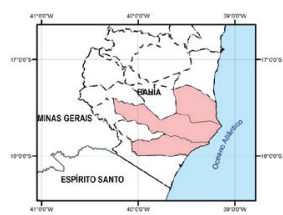

\begin{tabular}{|c|c|c|c|c|c|}
\hline \multicolumn{6}{|c|}{ Convenģöes } \\
\hline & & netria & \multicolumn{3}{|c|}{ Limite da paisagem em estudo } \\
\hline & & es municipais & \multicolumn{3}{|c|}{ Limites estaduais } \\
\hline \multicolumn{3}{|c|}{$\begin{array}{l}\text { Classes de Uso e } \\
\text { Ocupaçăo das Terras }\end{array}$} & Área $(\mathrm{km})$ & Porcentage & $n(\%)$ \\
\hline & & Solo Exposto & 2,37 & 0.41 & \\
\hline & & Area Urbana & 15.42 & 2,66 & \\
\hline & & Corpos d'Agua & 51,62 & 8,90 & \\
\hline & & Area Agricola & 44,37 & 7,65 & \\
\hline & & Area Florestal & 137,51 & 23,02 & \\
\hline & & Manguezais & 164,21 & 28.14 & \\
\hline & & Pastagem & 169,65 & 29,25 & \\
\hline 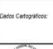 & & 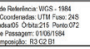 & ietaraser & $\stackrel{.}{=}$ & $=$ \\
\hline (x) & & 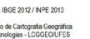 & $\operatorname{singen}_{\sin s}$ & oneras sura & $\infty{ }_{\text {aness } 233}$ \\
\hline
\end{tabular}

Figura 2- Mapa de uso e ocupação na Planície Costeira de Caravelas em 1984.

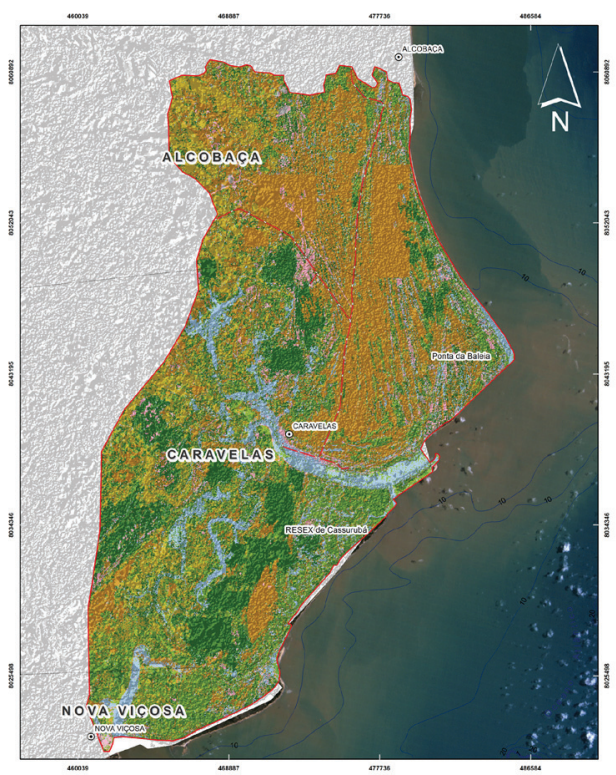

Uso e Ocupação das Terras na Região Planície Costeira de Caravelas em 1991

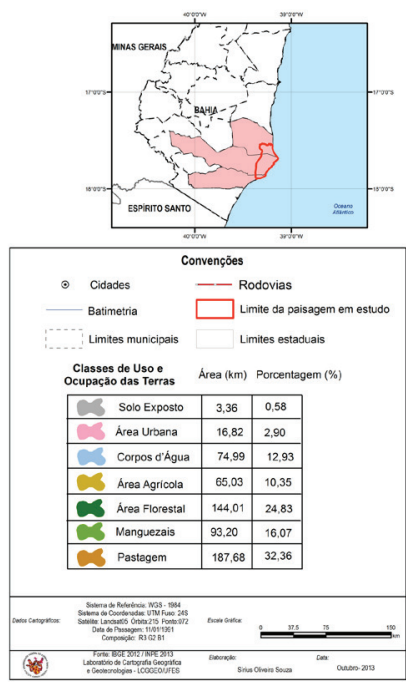

Figura 3- Mapa de uso e ocupação na Planície Costeira de Caravelas em 1991. 


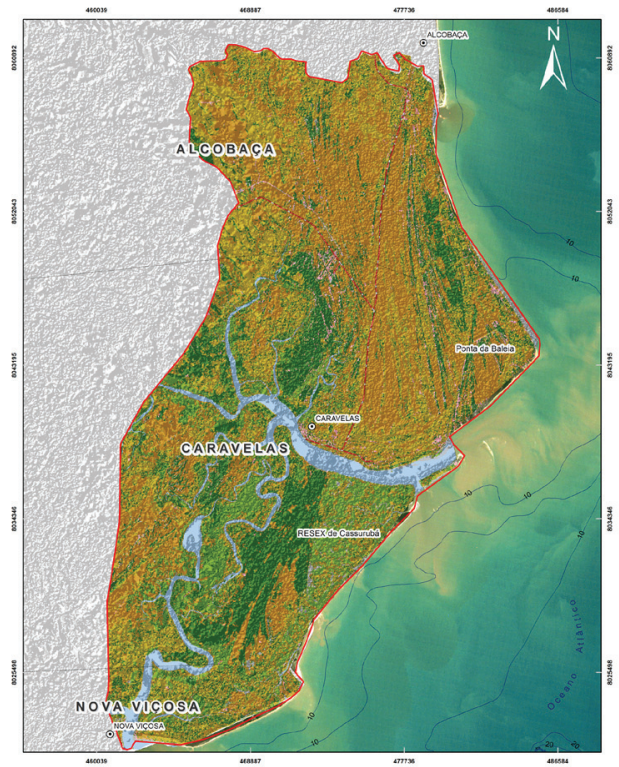

Uso e Ocupação das Terras na Região Planície Costeira de Caravelas em 2006

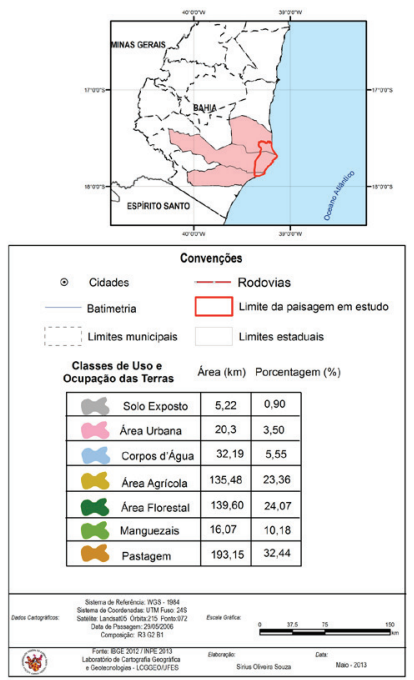

Figura 4- Mapa de uso e ocupação na Planície Costeira de Caravelas em 2006.

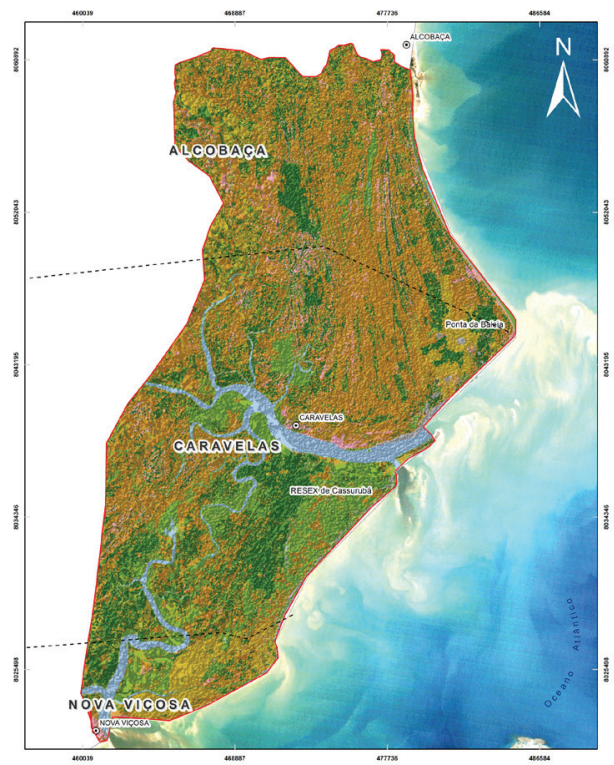

Uso e Ocupação das Terras na Planicie Costeira de Caravelas em 2011
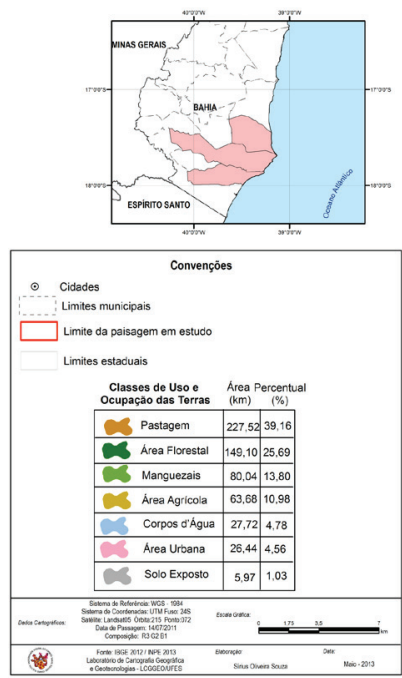

Figura 5- Mapa de uso e ocupação na Planície Costeira de Caravelas em 2011. 
Nos três primeiros anos analisados (1989, 1991 e 2006), observa-se também o impactante crescimento das áreas agrícolas (15,71\%) ocupando, em 2006, aproximadamente $135,48 \mathrm{~km}^{2}$, fato que se relaciona à contínua expansão da silvicultura de eucalipto e também com a expansão de outros cultivos, tais como: cana-de-açúcar, mamão e mandioca. No entanto, no período posterior (2006-2011), percebe-se uma redução de 12,38\% das áreas agrícolas, que pode ser relacionada à instituição da Reserva Extrativista de Cassurubá em 2007, e à substituição de lavouras pela vegetação tradicional.

Nota-se, em todo o período estudado, um leve crescimento das áreas urbanas, resultando em uma expansão de aproximadamente $11,02 \mathrm{~km}^{2}$. Tal crescimento tem se dado graças ao estabelecimento de segundas residências e de equipamentos turísticos. Observa-se especialmente a urbanização de áreas próximas a Ponta da Baleia, no trecho norte da área em estudo, justificado pela facilidade de acesso e disponibilidade de vias terrestres, em comparação ao trecho sul da Região Planície Costeira de Caravelas.

As áreas florestais, representadas, sobretudo, pela presença da Floresta Ombrófila Densa em estágio avançado de antropização, pela presença de Mata Seca de Restinga e demais vegetações associadas, apresentaram um fraco crescimento no período estudado, aproximado em 11,6 km². Tal crescimento pode ser associado à possível recuperação de trechos de Floresta Ombrófila Densa, em Áreas de Preservação Permanente e Reservas Legais, e também à gradativa recuperação de áreas pertencentes à Resex de Cassurubá. Vale ressaltar que, entre o segundo e o terceiro períodos estudados, evidencia-se a supressão de $4,41 \mathrm{~km}^{2}$.

Ocupando grandes extensões da Região Planície Costeira de Caravelas, e perfazendo importante papel na manutenção dos manguezais e brejos, estes últimos causam preocupação por apresentarem, nos três primeiros períodos, uma drástica redução de 17,96\%. A posterior recuperação ocorrida de 3,62\% pode não configurar um estágio mínimo de recuperação ideal da paisagem, visto que apenas 20,99 $\mathrm{km}^{2}$ de 104,168 $\mathrm{km}^{2}$ se recuperaram. Considerando os manguezais e brejos como áreas recobertas por manguezais, áreas brejosas e bancos arenosos expostos, evidencia-se a sua possível substituição por áreas agrícolas, pastagens e/ ou áreas urbanas.

As áreas de solo exposto apresentam um aumento progressivo de aproximadamente $3,6 \mathrm{~km}^{2}(0,62 \%)$, o que provavelmente denota a pró-gradação lateral da linha de costa efetuada principalmente por meio do cres- 
cimento de pontais arenosos no trecho norte da Região Planície Costeira de Caravelas, fato já discutido por Andrade et al. (2003), Azevedo, Guerra e Cabral (2005), dentre outros autores.

Nos dois primeiros períodos analisados, percebe-se um aumento de 4,03\% das áreas de corpos d'água, o que denota cerca de $23.374 \mathrm{~km}^{2}$. Esse fato pode estar relacionado ao período retratado na segunda amostragem orbital, visto que ela se refere ao Solstício de Verão. Fora isso, em todo o período estudado, nota-se a redução de 4,12\% dos corpos d'água, o que, possivelmente, pode ser relacionado à expansão das áreas agrícolas, urbanas e/ou pastagens, que apresentam cotidianamente a prática de substituição de áreas úmidas e/ou periodicamente inundadas por aterros e lavouras.

Uso e ocupação da Região Planície Costeira de Caravelas: diagnósticos e possíveis cenários

Nesta seção, são apresentadas algumas descrições sobre as formas de uso e de ocupação da terra encontradas durante os trabalhos de campo realizados e, na Tabela 3 e na Figura 6, constam alguns possíveis cenários, ${ }^{4}$ classificados mediante o estudo do comportamento espectral, em ambiente de expansão ou redução.

Diagnósticos de campo permitem inferir que as pastagens continuam a representar a matriz de uso e ocupação na Planície Costeira de Caravelas e tendem a uma alta expansão (Tabela 3). Estas se encontram em diversos estágios de degradação, apresentando extensas áreas abandonadas e submetidas aos processos de erosão laminar e em sulco, o que contribui para o assoreamento dos rios margeantes.

Nas áreas agrícolas, predominam o cultivo da cana-de-açúcar (Figura 6h), do coco-da-baía (Figura 6f) e da silvicultura do eucalipto (Figura 6g). Essas culturas apresentam uma tendência futura à baixa expansão e atestam, em distintos pontos, a falta de cuidado com os ecossistemas presentes ao encontrarmos lavouras e cultivos extremamente próximos aos cursos fluviais, fato que está em desacordo com o Código Florestal contemporâneo (Lei n. 12.651, de 25 de maio de 2012), que considera como Área de Preservação Permanente as faixas marginais de qualquer curso d'água natural perene e intermitente, desde a borda da calha do leito regular, em largura mínima de 30 metros. 
Tabela 3- Evolução do uso e ocupação da terra na Planície Costeira de Caravelas.

\begin{tabular}{|l|c|c|c|c|c|c|c|c|l|}
\hline \multirow{2}{*}{ Tipos de uso } & \multicolumn{2}{|c|}{1984} & \multicolumn{2}{|c|}{1991} & \multicolumn{2}{|c|}{2006} & \multicolumn{2}{|c|}{2011} & \multirow{2}{*}{} \\
\cline { 2 - 9 } & Área & Área & Área & Área & Área & Área & Área & Área & \\
\cline { 2 - 9 } & $(\mathrm{km})$ & $(\%)$ & $(\mathrm{km})$ & $(\%)$ & $(\mathrm{km})$ & $(\%)$ & $(\mathrm{km})$ & $(\%)$ & Diagnósticos \\
\hline Pastagens & 169,65 & 29,25 & 187,68 & 32,36 & 193,15 & 32,44 & 227,52 & 39,16 & expansão \\
\hline Área florestal & 137,51 & 23,02 & 144,01 & 24,83 & 139,60 & 24,07 & 149,10 & 25,69 & expansão \\
\hline $\begin{array}{l}\text { Manguezais e } \\
\text { manguezais e } \\
\text { brejos }\end{array}$ & 164,21 & 28,14 & 93,20 & 16,07 & 59,04 & 10,18 & 80,04 & 13,80 & redução \\
\hline Área agrícola & 44,37 & 7,65 & 65,03 & 10,35 & 135,48 & 23,36 & 63,68 & 10,98 & expansão \\
\hline Corpos d'água & 51,62 & 8,90 & 74,99 & 12,93 & 32,19 & 5,55 & 27,72 & 4,78 & redução \\
\hline Área urbana & 15,42 & 2,66 & 16,82 & 2,90 & 20,3 & 3,50 & 26,44 & 4,56 & expansão \\
\hline Solo exposto & 2,37 & 0,41 & 3,36 & 0,58 & 5,22 & 0,90 & 5,97 & 1,03 & expansão \\
\hline Totais & $\mathbf{5 8 0 , 5}$ & $\mathbf{1 0 0}$ & $\mathbf{5 8 0 , 5}$ & $\mathbf{1 0 0}$ & $\mathbf{5 8 0 , 5}$ & $\mathbf{1 0 0}$ & $\mathbf{5 8 0 , 5}$ & $\mathbf{1 0 0}$ & \\
\hline
\end{tabular}

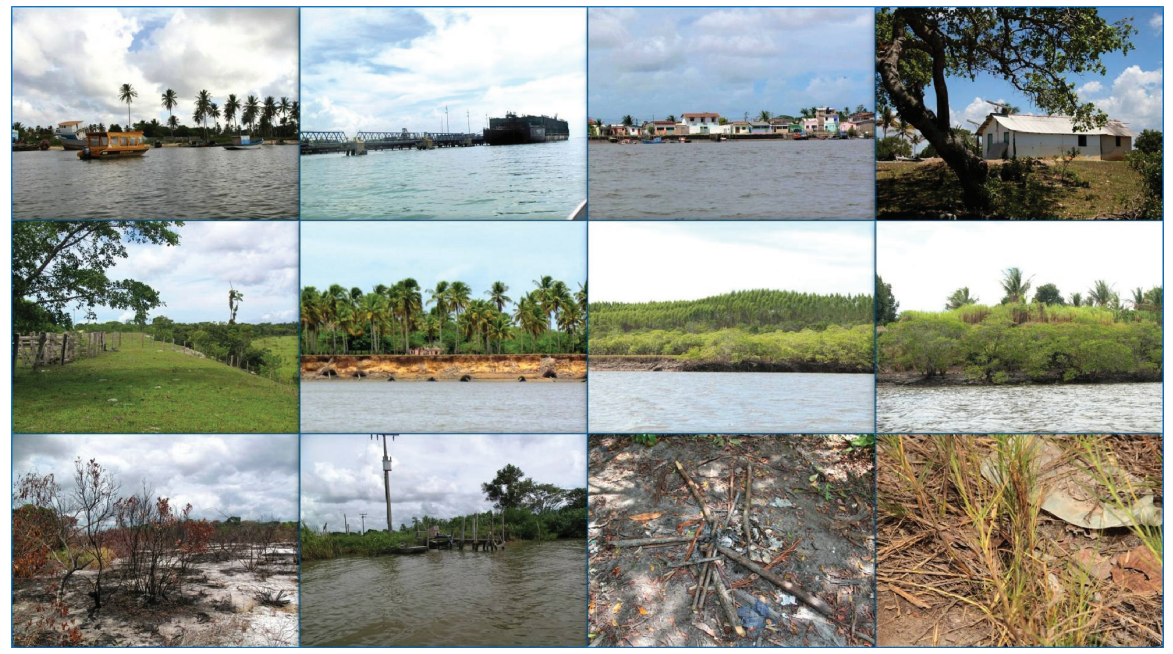

Figura 6- Registros de uso e ocupação das terras na Região Planície Costeira de Caravelas: área urbana $(a, c, d)$; terminal de barcaças da Fíbria (b); pastagem em terraços arenosos (e); área agrícola $(\mathrm{f}, \mathrm{g}, \mathrm{h})$; queimada em áreas de área florestal (i); captação ilegal de água em trecho do rio Caribê (j); registro de fogo e aterramentos em área de manguezais e brejos $(k, l)$. 
Relacionando-se com as áreas agrícolas, as áreas urbanas apresentam um crescimento desordenado e ilustram o recente processo de concentração fundiária, de diminuição do número de empregados no campo e a reorganização socioeconômica, uma consequência direta da implantação da silvicultura de eucalipto na região (IBGE, 2012). Ambas tendem à baixa expansão.

As áreas florestais apresentam-se em estado moderado de conservação e com uma tendência futura à expansão, conforme ilustrado na Figura 7, fato já discutido por Dominguez (2008). Durante o trabalho de campo, observou-se a ação do fogo em extensas áreas de Mata Seca de Restinga, conforme ilustra a Figura 6i, uma evidência que justifica a necessidade de estudos sobre a susceptibilidade aos incêndios.

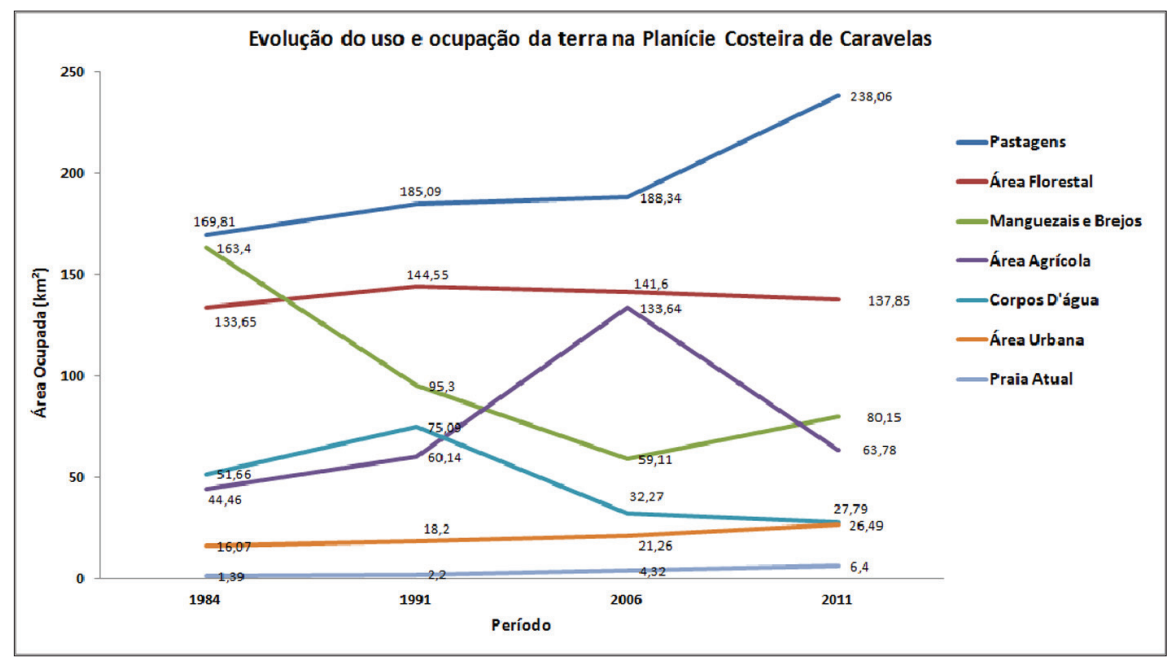

Figura 7- Evolução do uso e ocupação da terra na Planície Costeira de Caravelas.

Os manguezais e corpos d'água abrangem extensas áreas da Região Planície Costeira de Caravelas e agrupam ecossistemas demarcados pelo uso comercial e pela pesca artesanal de crustáceos e moluscos. As Figuras $6 \mathrm{i}, 6 \mathrm{k}$ e $6 \mathrm{j}$ ilustram o uso indiscriminado dessas áreas, por meio da presença de fogo, captação ilegal de água e aterramentos. Tais evidências confirmam a preocupante tendência destas áreas à alta redução.

As áreas de solo exposto (Figura 7) configuram extensas praias arenosas com tendência à expansão e representam, junto com as atividades 
agropecuárias, um importante vetor econômico polarizador da Região Planície Costeira de Caravelas.

\section{Considerações finais}

A metodologia utilizada neste artigo, pautada em análises espectrais e rotinas de SIG, não dispensou o trabalho de campo. Embora o geoprocessamento apresente índices confiáveis, a quantificação associada à escala em que o trabalho foi desenvolvido poderia mascarar fenômenos específicos e suas particularidades. Considera-se, todavia, que as técnicas de Sensoriamento Remoto aplicadas se mostraram eficientes para a escala de estudo proposta (1:150.000) e que os trabalhos de campo, somados ao software utilizado, mostraram-se eficazes, permitindo a integração dos mapas temáticos e dando origem a diferentes interpretações.

Quanto à evolução do uso e da ocupação da terra nos últimos 29 anos, ficou constatado que as mudanças ocorridas na Planície Costeira de Caravelas podem refletir um modelo econômico vigente no Brasil, cuja ocupação da zona costeira se dá de forma desordenada, sem considerar a importância dos ecossistemas ali existentes. Comprova-se com este estudo a gradativa expansão da área agrícola, da área urbana e da pastagem, com diferentes tendências. Paralelamente, há uma redução das áreas ocupadas pelos corpos d'água e pelos manguezais e brejos. Por outro lado, observou-se crescimento das áreas florestais, sobretudo da Mata Seca de Restinga.

Percebe-se a necessidade do desenvolvimento de pesquisas nesta área, visando à valorização e preservação tanto do ambiente natural quanto do patrimônio histórico-cultural, embasadas em instrumentos que contribuam com a minimização dos efeitos negativos da ação antrópica.

Um estudo como este se torna importante na medida em que pode ser utilizado como um norteador das políticas de gestão para aquela parte da zona costeira, de forma que as novas ocupações e o desenvolvimento econômico e social sejam compatibilizados com a preservação ambiental. Fica clara a necessidade de estudos mais detalhados, com imagens de satélite com melhor resolução espacial, para se obter uma delimitação de uso mais precisa, que vise atender às necessidades do homem e à manutenção dos recursos costeiros. 


\section{Notas}

1. Pesquisa financiada pela Fundação de Amparo à Pesquisa do Estado do Espírito Santo sob o número de registro 590064631/2012 na modalidade bolsa de Mestrado.

2. A Reserva Extrativista de Cassurubá é uma unidade de conservação federal do Brasil categorizada como reserva extrativista e criada por Decreto Presidencial em 5 de junho de 2009, numa área de 100.687 hectares, nos municípios de Alcobaça, Caravelas e Nova Viçosa, no estado da Bahia. A Resex também beneficia cerca de 20.000 pessoas que vivem da pesca nessa região (Souza, 2013).

3. Entende-se por classificação híbrida o resultado entre a classificação digital e a interpretação visual (Azevedo e Mangabeira, 2001).

4. Ressalva-se que a denominação cenários possíveis pauta-se apenas no estudo do comportamento espectral, desconsiderando, portanto, outras possíveis variáveis.

\section{Referências}

ANDRADE, A. C. S.; DOMINGUEZ, J. M. L.; MARTIN, L.; BITTENCOURT, A. C. S. P. Quaternary evolution of the Caravelas strandplain - Southern Bahia State Brazil. Anais Academia Brasileira de Ciências, Rio de Janeiro, v. 75, n. 3, p. 357382, 2003.

ANDRADE, A. C. S.; DOMINGUEZ J. M. L. Informações geológico-geomorfológicas como subsídios à análise ambiental: o exemplo da Região Planície Costeira de Caravelas (BA). Boletim Paranaense de Geociências, Paraná, v. 51, p. 9-17, 2002.

AZEVEDO, E. C. de; MANGABEIRA, J. A. de C. Mapeamento de uso das terras utilizando processamento digital de imagens de sensoriamento remoto. Campinas (SP): Ministério da Agricultura, Pecuária e Abastecimento. (Comunicado Técnico, 7). 2001.

AZEVEDO, I. F.; GUERRA, J. V.; CABRAL, A. P. Evolução geomorfológica de pontais arenosos associados à foz de rios na orla da Planície de Caravelas (BA). Anais X Congresso da ABEQUA, Guarapari (ES), 2005.

BERNARDES, J. A.; FERREIRA, F. P. M. Sociedade e natureza. In: CUNHA, S. B.; GUERRA, A. J. T. (Orgs.). A questão ambiental: diferentes abordagens. Rio de Janeiro: Bertrand Brasil, 2003. p. 17-42.

BRASIL. Lei n. 12.651, de 25 de maio de 2012. Dispõe sobre a proteção da vegetação nativa; altera as Leis n. 6.938, de 31 de agosto de 1981; 9.393, de 19 de dezembro de 1996; e n. 11.428, de 22 de dezembro de 2006; revoga a Lei n. 4.771, de 15 de setembro de 1965; e n. 7.754, de 14 de abril de 1989, e a Medida Provisória n. 2.166-67, de 24 de agosto de 2001; e dá outras providências. Portal da Legislação: Leis Ordinárias. 2013. Disponível em: <http://www.planalto.gov.br/ccivil_03/_ Ato2011-2014/2012/Lei/L12651.html>. Acesso em: 15 set. 2013. 
DOMINGUEZ, J. M. L. (Org.). Costa das Baleias: caracterização da Zona Costeira dos municípios de Alcobaça, Caravelas, Nova Viçosa e Mucuri. Salvador: CBPM/ UFBA-CPGG/LEC, 2008.

FONTES, E. de O.; MELLO E SILVA, S. C. B. de. Desigualdades regionais no extremo sul da Bahia: desafios e oportunidades. Observatório Geográfico da América Latina, 2005.

INSTITUTO BRASILEIRO DE GEOGRAFIA E ESTATÍSTICA (IBGE). Climas do Brasil. 2007. Disponível em: <http://www.ibge.gov.br/home/geociencias/ recursosnaturais/mapas/mapas_doc4.shtm>. Acesso em: 12 dez. 2013.

. Banco de Dados Agregados. Sistema IBGE de Recuperação AutomáticaSIIDRA. 2012. Disponível em: http://www.ibge.gov.br. Acesso em: 22 out. 2013.

. Manual Técnico do uso da Terra. 2013. Disponível em: $<$ http $<<$ ://www. ibge.gov.br/home/geociencias/recursosnaturais/usodaterra/manual_usodaterra. shtml>. Acesso em: 12 jan. 2014.

LIMONAD, E. "Você já foi à Bahia, nêga? Não! Então vá! Antes que acabe...”. Planejamento, urbanização e turismo no litoral do Nordeste brasileiro, tendências e perspectivas. Scripta Nova. Revista Electrónica de Geografía y Ciencias Sociales. Barcelona: Universidad de Barcelona. V.X II, n. 270. 2008. Disponível em: <http:// www.ub.es/geocrit/sn/sn-270/sn-270-55.htm>. Acesso em: 10 ago. 2012

MATIAS, L. F. Sistema de Informações Geográficas (SIG): teoria e método para representação do espaço geográfico. Tese (Doutorado) - FFLCH, Universidade de São Paulo, São Paulo, 2001.

MOREIRA, M. A. Fundamentos do sensoriamento remoto e metodologias de aplicação. 3. ed. Viçosa: Ed. UFV, 2005.

MORAES, A. C. R. Contribuições para a gestão da zona costeira do Brasil: elementos para uma geografia do litoral brasileiro. São Paulo: Annablume, 2007.

NASCIMENTO D. M. C.; DOMINGUEZ J. M. L. Avaliação da vulnerabilidade ambiental como instrumento de gestão costeira nos municípios de Belmonte e Canavieiras, Bahia. Revista Brasileira de Geociências, v. 39, p. 395-408, 2009.

NICOLODI, J. L.; PETERMANN, R. M. Mudanças climáticas e a vulnerabilidade da Zona Costeira do Brasil: aspectos ambientais, sociais e tecnológicos. Revista da Gestão Costeira Integrada, v. 10, n. 2, p. 151-177, 2010.

ROSA, R. Geotecnologias na geografia aplicada. Revista do Departamento de Geografia, Uberlândia, n. 16, p. 81-90, 2005.

SOUZA, M. de L. C.; GERMANI, G.; SOUZA, E. R. L. C. Conflitos de interesses na produção do espaço na área costeira do litoral norte da Bahia. Anais do $I^{o}$ Seminário Espaços Costeiros, 2011.

SOUZA. S. O. Vulnerabilidade ambiental da planície costeira de Caravelas (Bahia): uma proposta geossistêmica. Tese (Dissertação) - Pós-Graduação em Geografia, UFES, Vitória, 2013. 
Sirius Oliveira Souza - Possui Especialização em ensino de Geografia pela Universidade Estadual de Santa Cruz. Mestrado em Geografia pela Universidade Federal do Espírito Santo. Atualmente é Doutorando em Geografia pela Universidade Estadual de Campinas.

Recebido para publicação em novembro de 2014 Aceito para publicação em janeiro de 2015 